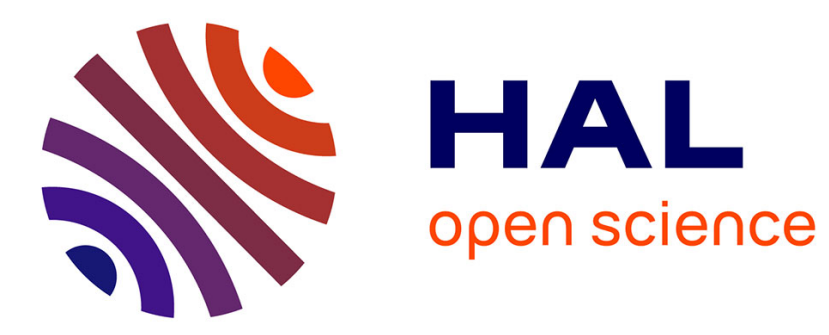

\title{
Non-Intrusive Estimation of the Loss Resistance of a Planar antenna Over the Human Body
}

\author{
Thierry Alves, Benoit Poussot, Jean-Marc Laheurte
}

\section{To cite this version:}

Thierry Alves, Benoit Poussot, Jean-Marc Laheurte. Non-Intrusive Estimation of the Loss Resistance of a Planar antenna Over the Human Body. Electronics Letters, 2013, 49 (19), pp.1200-1201. hal00864701

\section{HAL Id: hal-00864701 \\ https://hal.science/hal-00864701}

Submitted on 7 Sep 2016

HAL is a multi-disciplinary open access archive for the deposit and dissemination of scientific research documents, whether they are published or not. The documents may come from teaching and research institutions in France or abroad, or from public or private research centers.
L'archive ouverte pluridisciplinaire HAL, est destinée au dépôt et à la diffusion de documents scientifiques de niveau recherche, publiés ou non, émanant des établissements d'enseignement et de recherche français ou étrangers, des laboratoires publics ou privés. 


\section{Non-intrusive estimation of loss resistance of planar antenna over human body}

\section{T. Alves, B. Poussot and J.-M. Laheurte}

A new method is presented to estimate the loss resistance of antennas located slightly above a lossy medium. This technique is more specifically developed for the context of body area networks. This method is based on the estimation of the antenna resistance above the medium and above a perfect electric conductor

Introduction: The 'Wheeler cap method' [1] is the most commonly used method to estimate the efficiency of small antennas. This consists in enclosing the antenna with a metallic box that is large enough to not disturb the reactive near field and cancel the antenna radiation (typically cap dimensions should be greater than $\lambda / 2 \pi$ ). The antenna efficiency is then calculated from the knowledge of the antenna impedance with and without the Wheeler cap.

However, in the presence of any lossy medium, the induced currents into it can be seen as an extension of the antenna body [2]. As a result, the total reactive field is contained in a nearly $\lambda / 2$ diameter sphere [3] which, in turn, involves a bigger Wheeler cap.

In the context of body area networks (BANs), antennas are in the vicinity of the body, a lossy medium whose composition $[4,5]$ may largely vary. In [6], the Wheeler cap method was applied to BAN antennas with small ground planes partially including the phantom inside the cap. Other authors have introduced the 'body-worn efficiency' [7] which is the ratio of the in-body 'radiated power' to the free space radiated power.

The methods described above either require a field measurement inside a body phantom or an unpractical Wheeler cap overlapping body tissues. This Letter proposes a simple method based on the compensation theorem to estimate the loss resistance of BAN antennas. From the simulated or measured values of the input resistance of the antenna, first above the body tissues, then above a metallic ground plane, it is possible to extract the loss resistance above the body tissues. Knowing the loss resistance $R_{\mathrm{L}}$ and the total input resistance $R_{\text {in }}$, it is further possible to deduce the antenna efficiency $\eta=1-R_{\mathrm{L}}$ $R_{\text {in }}$ in the presence of the body.

Compensation theorem: The compensation theorem applied in electromagnetics was first demonstrated by Monteath [8]. It gives the impedance variation $\Delta Z$ between the impedance $Z$ of the antenna located above a lossy medium and the impedance $Z_{\mathrm{PEC}}$ of the same antenna located above a perfect electric conductor (PEC) $[9,10]$

$$
\Delta Z=Z-Z_{\mathrm{PEC}}=\frac{1}{I_{0}^{2}} \int_{\mathrm{S}} H_{/ /}^{2} Z_{\mathrm{s}} \mathrm{d} S
$$

- $Z_{\mathrm{s}}$ : surface impedance modelling of the lossy medium

- $Z$ : impedance of the antenna over the lossy medium

- $Z_{\mathrm{PEC}}$ : impedance of the antenna above a PEC

- $\Delta Z$ : impedance increment

- $H_{/ /}$: tangential magnetic field over a PEC

- $I_{0}$ : root-mean-square current value at the antenna feeding point

- $S$ : boundary surface exhibiting a surface impedance $Z_{\mathrm{s}}$.

Power considerations: Comparing the power delivered to the antenna over a PEC and over a lossy medium, we exploit (1) to show that an antenna over a lossy medium consumes an additional power that is

$$
\Delta P=R\{\Delta Z\} I_{0}^{2}=R\left\{\int_{\mathrm{S}} H_{/ /}^{2} Z_{\mathrm{s}} \mathrm{d} S\right\}
$$

This leads to an increment of power given by

$$
\Delta P=\int_{\mathrm{S}}\left|H_{/ /}\right|^{2}\left|Z_{\mathrm{s}}\right| \cos \left(\varphi_{\mathrm{s}}+2 \varphi_{\mathrm{h}}\right) \mathrm{d} S
$$

where $\varphi_{s}$ is the phase of the surface impedance and $\varphi_{h}$ is the phase of the tangential magnetic field. On the other hand, the power $P_{\mathrm{L}}$ absorbed by any lossy medium is given by the well-known formula

$$
P_{\mathrm{L}}=\int_{\mathrm{S}}\left|H_{/ /}\right|^{2}\left|Z_{\mathrm{s}}\right| \cos \varphi_{\mathrm{S}} \mathrm{d} S
$$

From (2b) and (3), it is clear that $P_{\mathrm{L}}$ and $\Delta P$ are equal when $\varphi_{h}$ is small. This is verified when the antenna is close to the medium $[9,10]$. Therefore, we conclude that when an antenna is close to a lossy medium, the additional consumed power is mainly due to the medium losses. Under this condition, the loss resistance $R_{\mathrm{L}}$ of the antenna is given by

$$
R_{\mathrm{L}} \simeq R\{\Delta Z\}
$$

The method presented in this Letter is based on this assumption. Estimation of loss resistance: To control the validity of (4), we compare the $R_{\mathrm{L}}$ values determined by two methods:

\section{a. $R_{\mathrm{L}}$ determined from (4) and $4 \mathrm{NEC} 2$ simulations [11]:}

- Computation of the antenna impedance $Z$ over a lossy medium

- Computation of the antenna impedance $Z_{\mathrm{PEC}}$ over a PEC

- Use of (4): $\mathfrak{R}\{\Delta Z\}=\Re\left\{Z-Z_{\mathrm{PEC}}\right\}=R_{\mathrm{L}}$.

It is important to note that this method can also be applied experimentally.

b. $R_{\mathrm{L}}$ determined from the following relation using the HFSS calculations of the antenna impedance $Z$ and the efficiency $\eta$ in the presence of a lossy medium:

$$
R_{\mathrm{L}}=R\{Z\}(1-\eta)
$$

The comparison between these methods is realised at $2.4 \mathrm{GHz}$ for a halfwavelength horizontal dipole (radius $=\lambda_{0} / 250$ and metallisation $=\mathrm{PEC}$ ) and the integrated inverted-F antenna (IIFA) depicted in Fig. 1. The medium characteristics of the semi-infinite lossy medium used in the HFSS simulations are those of an available homogeneous torso phantom. The phantom relative permittivity and loss tangent $\left(\varepsilon_{\mathrm{r}}=27\right.$ and $\tan \delta=0.505$ ) are extracted from measurements based on the openended coaxial probe technique.

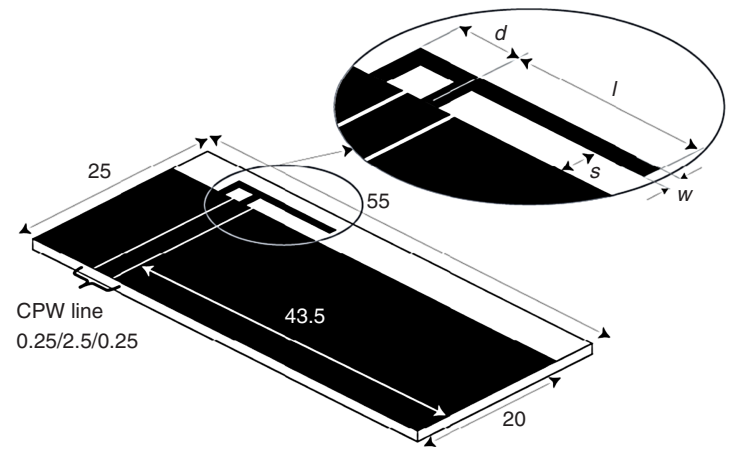

Fig. 1 Details of IIFA

Dimensions: $w=1 \mathrm{~mm}, s=2 \mathrm{~mm}, l=10.5 \mathrm{~mm}, d=3.5 \mathrm{~mm}$ FR4 substrate $\left(\varepsilon_{\mathrm{r}}=4.4, \tan \delta=0.02\right)$; thickness $=1.6 \mathrm{~mm}$

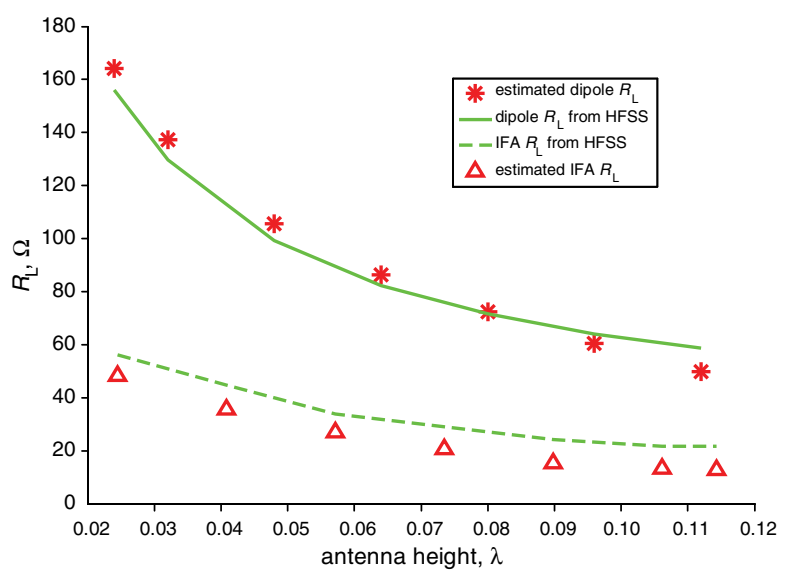

Fig. 2 Loss resistance of half-wavelength dipole and IIFA Comparison between two methods

The loss resistance is given for both antennas in Fig. 2 as a function of the normalised height $h / \lambda_{0}$ above the medium interface. A good 
agreement is observed between the two methods. However, it must be stressed that the relative differences are 2 and $8 \%$ for $h=\lambda_{0} / 40$, and 17 and $25 \%$ for $h=\lambda_{0} / 10$ with the IIFA and the dipole, respectively. This increasing divergence for larger heights flows from the approximations in (4) that are not valid for large $h / \lambda_{0}$, i.e. the phase of the tangential magnetic field is no longer negligible on the body surface in the vicinity of the antenna. We conclude that the $R_{\mathrm{L}}$ estimation based on the compensation theorem is valid in the body context as long as the height above the interface is lower that $\lambda_{0} / 10$, approximately $(1.25 \mathrm{~cm}$ at $2.4 \mathrm{GHz}$ ), which is sufficient in most BAN scenarios.

Measurements are realised with the IIFA, first on the torso phantom, then on a large copper plate. Special care is taken to avoid cable radiations from the flow of external current with baluns made of a pair of $\lambda / 4$ stubs. Tunable plastic spacers are used to fix the antenna heights above the phantom surface. $R_{\mathrm{L}}$ is then deduced from the procedure described above and compared with the value obtained with the same procedure using the HFSS impedance values. In Fig. 3, the $R_{\mathrm{L}}$ curves follow the same trend. Discrepancies can be attributed to the difficulty in measuring the correct impedance in small antennas where the antenna body extends partially to the cable and the balun structure. In addition, the presence of the antenna connector and cable in the vicinity of the interface perturbs the measurements.

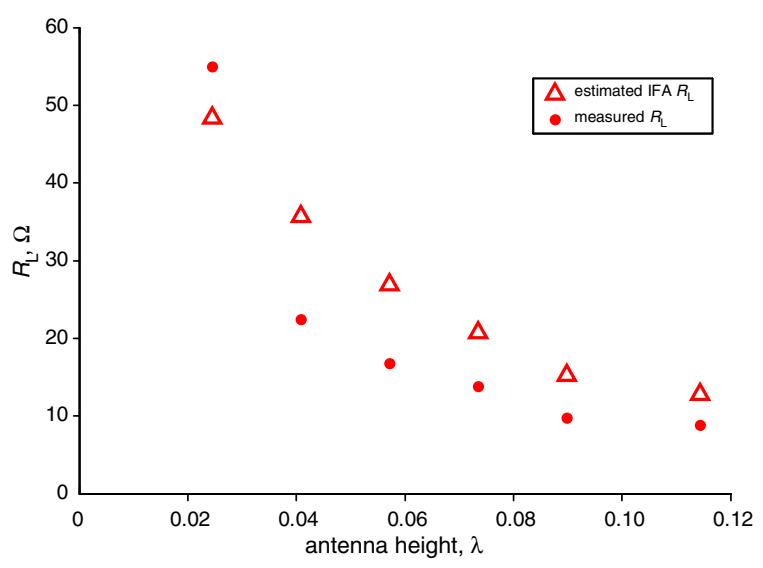

Fig. 3 Estimation of IIFA loss resistance based on compensation theorem Comparison of experimental and simulated results

Conclusion: A new technique has been described to estimate the loss resistance of an antenna close to a lossy interface. The method is based on the knowledge of the antenna resistance above a lossy surface and above a PEC. It has been validated using two numericalbased estimations of $R_{\mathrm{L}}$. It can also be applied experimentally by measuring the antenna resistance first above a lossy medium then above a metallic ground plane. A straightforward application is the BAN context, in which Wheeler caps are unpractical because they should include some volume of the body or phantom.

(C) The Institution of Engineering and Technology 2013

21 June 2013

doi: $10.1049 / \mathrm{el} .2013 .2054$

One or more of the Figures in this Letter are available in colour online.

T. Alves, B. Poussot and J.-M. Laheurte (ESYCOM, Université ParisEst Marne-la-Vallée, 77454 Marne-la-Vallée Cedex 2, France)

E-mail: laheurte@univ-mlv.fr

\section{References}

1 Wheeler, H.A.: 'The radiansphere around a small antenna', Proc. IRE, August 1959, vol. 47, pp. 1325-1331

2 Monteath, G.D.: 'The effect of the ground constants, and of an earth system, on the performance of a vertical medium-wave aerial', Part C: Monographs, 105, (7), pp. 292-306

3 Trainotti, V., and Dorado, L.A.: 'Short low- and medium-frequency antenna performance', IEEE Antennas Propag. Mag., 2005, 47, (5), pp. 66-90

4 Alves, T.: 'Conception d'Antennes pour le Réseau BAN et Modélisation du Canal de Propagation'. PhD thesis, Université Paris Est Marne-la-Vallée, 2012, EA2552

5 Christ, A., Klingenböck, A., Samaras, T., Goiceanu, C., and Kuster, N.: 'The dependence of electromagnetic far-field absorption on body tissue composition in the frequency range from $300 \mathrm{MHz}$ to $6 \mathrm{GHz}$, IEEE Trans. Microw. Theory Tech., 2006, 54, (5), pp. 2188-2195

6 Salim, T., and Hall, P.S.: 'Efficiency measurement of antennas for on-body communications', Microw. Opt. Technol. Lett., 2006, 48, (11), pp. 2256-2259

7 Kellomäki, T.: 'Effects of the human body on single-layer wearable antennas'. PhD thesis, Tampere University of Technology, 2012, Publication 1025

8 Monteath, G.D.: 'Application of the compensation theorem to certain radiation and propagation problems'. Part IV: Institution Monographs, 1951, 98, (1), pp. 23-30

9 Wait, J.R.: 'On the input impedance of a hertzian dipole over a flat surface', IEEE Trans. Antennas Propag., 1970, 18, (1), pp. 119-121

10 Wait, J.R.: 'Impedance characteristics of electric dipoles over a conducting half-space', Radio Sci., 1969, 4, (10), pp. 971-975

114 NEC2 is a free interface developed by Arie Voors to use the NEC2 engine. Available at http://www.qsl.net/4nec2/ 